\title{
EVALUATION OF DIGITAL ELEVATION MODELS FOR GEOMORPHOMETRIC ANALYSES ON DIFFERENT SCALES FOR NORTHERN CHILE
}

\author{
T. Kramm*, D. Hoffmeister \\ Institute of Geography, GIS \& RS Group, University of Cologne, Albertus-Magnus-Platz, 50923 Cologne, Germany - \\ (tanja.kramm, dirk.hoffmeister)@uni-koeln.de
}

Commission III, ICWG III/IVb

KEY WORDS: Accuracy Assessment, Chile, DEM, Topography, TPI, TRI, UAV

\begin{abstract}
:
The resolution and accuracy of digital elevation models (DEMs) have direct influence on further geoscientific computations like landform classifications and hydrologic modelling results. Thus, it is crucial to analyse the accuracy of DEMs to select the most suitable elevation model regarding aim, accuracy and scale of the study. Nowadays several worldwide DEMs are available, as well as DEMs covering regional or local extents. In this study a variety of globally available elevation models were evaluated for an area of about 190,000 $\mathrm{km}^{2}$. Data from Advanced Spaceborne Thermal Emission and Reflection Radiometer (ASTER) $30 \mathrm{~m}$, Shuttle Radar Topography Mission (SRTM) $30 \mathrm{~m}$ and $90 \mathrm{~m}$, Advanced Land Observing Satellite (ALOS) World 3D $30 \mathrm{~m}$ and TanDEM-X WorldDEM $^{\mathrm{TM}}-12 \mathrm{~m}$ and $90 \mathrm{~m}$ resolution were obtained. Additionally, several very high resolution DEM data were derived from stereo satellite imagery from SPOT 6/7 and Pléiades for smaller areas of about $100-400 \mathrm{~km}^{2}$ for each dataset. All datasets were evaluated with height points of the Geoscience Laser Altimeter System (GLAS) instrument aboard the NASA Ice, Cloud, and land Elevation (ICESat) satellite on a regional scale and with nine very high resolution elevation models from UAV-based photogrammetry on a very large scale. For all datasets the root mean square error (RMSE) and normalized median absolute deviation (NMAD) was calculated. Furthermore, the association of errors to specific terrain was conducted by assigning these errors to landforms from the topographic position index (TPI), topographic roughness index (TRI) and slope. For all datasets with a global availability the results show the highest overall accuracies for the TanDEM-X $12 \mathrm{~m}$ (RMSE: $2.3 \mathrm{~m}$, NMAD: $0.8 \mathrm{~m}$ ). The lowest accuracies were detected for the $30 \mathrm{~m}$ ASTER GDEM v3 (RMSE: $8.9 \mathrm{~m}$, NMAD: $7.1 \mathrm{~m}$ ). Depending on the landscape the accuracies are higher for all DEMs in flat landscapes and the errors rise significantly in rougher terrain. Local scale DEMs derived from stereo satellite imagery show a varying overall accuracy, mainly depending on the topography covered by the scene.
\end{abstract}

\section{INTRODUCTION}

Nowadays digital elevation models (DEMs) are mainly generated by remote sensing techniques. They are acquired by airborne or satellite imagery with optical stereoscopy, space-borne Interferometric Synthetic Aperture Radar (InSAR) or Light Detection and Ranging (LiDAR). The main advantage of these techniques is that large areas can be rapidly covered. The digital representation of the Earth's surface is important for many geospatial studies and applications, such as studies on landform distribution, geomorphology, plant distribution research, sediment transport estimation and hydrologic analysis (Bishop et al., 2012, Leempoel et al., 2015, Drisya \& Kumar, 2016, Kramm et al., 2017). Thus, it is crucial to analyse the accuracy of digital elevation models to select the most suitable one regarding to aim, accuracy and scale of the study. For instance, while the identification of large channel profiles over wide distances is easily possible even with $90 \mathrm{~m}$ resolution data, landscapes in large scales require DEMs with $1-30 \mathrm{~m}$ spatial resolution to identify individual hillslopes and ridges (Grieve et al., 2016a, Grieve et al., 2016b).

In the meantime, a variety of worldwide digital elevation models are available, as well as DEMs covering regional or local extents. However, these global DEMs usually are less accurate and capture less terrain details due to lower spatial resolution. In contrast, very high resolution elevation models derived by stereo satellite imagery offer a higher ground sampling distance (GSD) and vertical accuracy. But for larger areas they are often not suitable due to high cost and time-consuming processing. Therefore, they are only usable for large scale analyses.

The goal of this study is to conduct a comprehensive accuracy assessment of the vertical accuracy for a multitude of different DEMs, both for a regional coverage and for local coverages. The accuracy assessment was performed on two scales, one for a large region with elevation points from the Ice, Cloud, and land Elevation (ICESat) satellite and for several small areas with very accurate elevation data derived by Unmanned Aerial Vehicle (UAV)-based photogrammetry. Global available DEMs are primarily intended for analyses with a regional or global extent, thus it should be investigated to which degree they are also suitable for large scale terrain analyses as these require a more detailed terrain representation. Furthermore, the accuracy is addressed and evaluated with regard to the existing topography, because it is evident that terrain has a direct influence in accuracy (Holmes et al., 2000, Mukherjee et al., 2013).

\section{MATERIALS AND METHODS}

\subsection{Study area}

The study was conducted in the northern part of Chile (Fig. 1). The area covers the Chilean part of the Atacama Desert, represented by the administrative regions of Tarapacá and

\footnotetext{
* Corresponding author
} 
Antofagasta in northern Chile. The region is characterized by its hyper arid climate, which is one of the driest areas on Earth. Due to the lack of precipitation vegetated areas are hardly available.

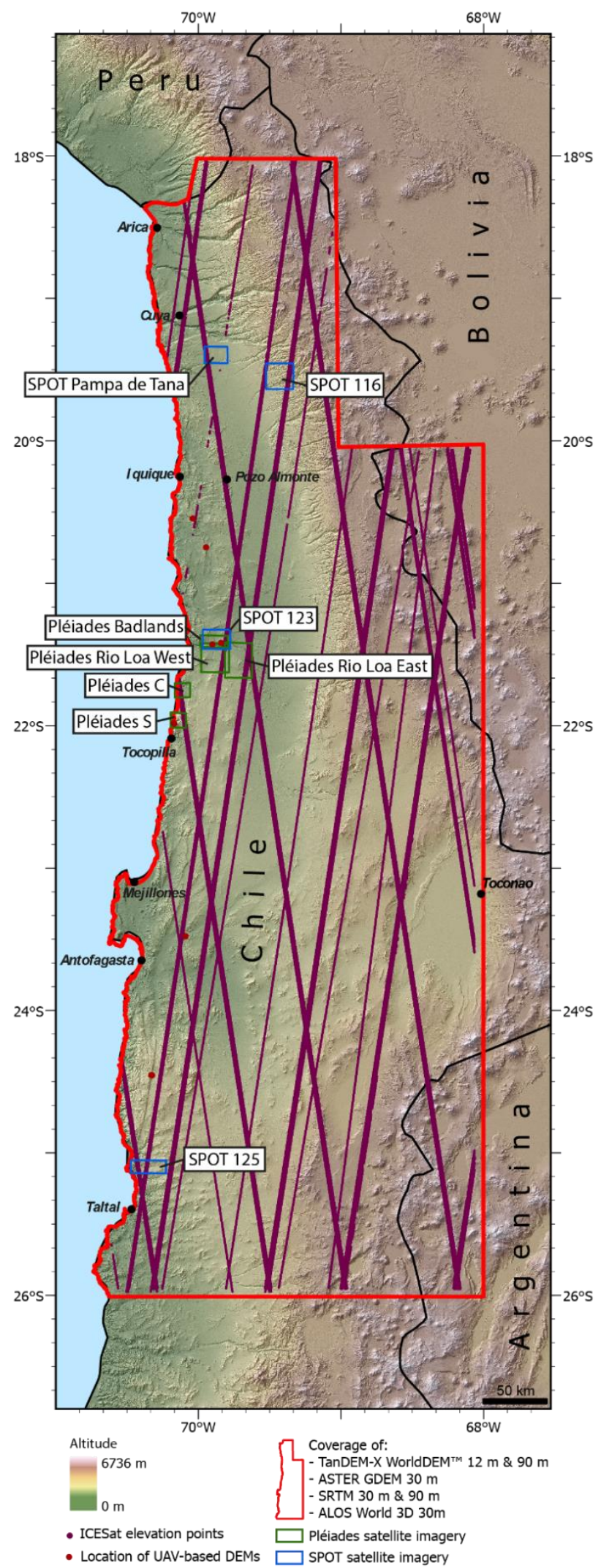

Figure 1. Overview map of study area and locations of DEMs and ground truth data. Map based on SRTM elevation data.
The relief is characterized by large height differences from the coast of the Pacific to the mountains of the Andes with altitudes up to $6700 \mathrm{~m}$ above sea level. Furthermore, the study area consists of a diverse topography with steep, seaward cliffs and deeply incised canyons, as well as large alluvial fans and volcanos in the mountain range of the Andes. Thus, the landscape offers a cross section of different relief types from flat and broad landscapes to steep and dissected terrain.

\subsection{Digital Elevation Models}

To validate the accuracy of digital elevation models several freely available DEMs with global coverage were regarded in this study:

- The $3^{\text {rd }}$ Version of the Advanced Spaceborne Thermal Emission and Reflection Radiometer Global DEM (ASTER GDEM), which was released in 2011 by the NASA and the Japanese Ministry of International Trade and Industry. The digital elevation model has a spatial resolution of 1 arcsecond $(\sim 30 \mathrm{~m})$

- The Advanced Land Observing Satellite (ALOS) World 3D (AW3D), released by the Japan Aerospace Exploration Agency (JAXA). A $30 \mathrm{~m}$ DEM was generated from images acquired by the optical Panchromatic Remote-sensing Instrument for Stereo Mapping (PRISM) sensor on board of the ALOS satellite (Takaku et al., 2014, Tadono et al., 2014).

- The digital elevation model from the Shuttle Radar Topography Mission (SRTM) Version 4, released by the Consultative Group of International Agricultural ResearchConsortium for Spatial Information (CGIAR-CSI) (Farr et al., 2007). In this contribution the versions with a spatial resolution of $30 \mathrm{~m}$ and $90 \mathrm{~m}$ were used.

- The TanDEM-X WorldDEM ${ }^{\mathrm{TM}}$, which was created and provided by the German Aerospace Centre and is subsequently denoted as 'TanDEM-X', was used in the resolutions of $12 \mathrm{~m}$ and $90 \mathrm{~m}$.

All of these DEMs were evaluated for an area of around 190,000 km² (Fig. 1).

Additionally, nine digital elevation models were derived from high resolution stereo satellite imagery. As these elevation models have a relative high spatial resolution they cover only smaller regions of about $100-400 \mathrm{~km}^{2}$ coverage of each scene. Five elevation models were derived from Pléiades imagery and four from SPOT 6 and 7 stereo images, all provided by the French Space Center (CNES). All DEMs were processed with the software PCI Geomatica 2018 OrthoEngine with automatic Ground Control Point and Tie-Point collection. All derived Pléiades and SPOT DEMs were resampled to a spatial resolution of $5 \mathrm{~m}$.

\subsection{Accuracy Assessment}

For a vertical accuracy assessment, a highly accurate evaluation data is necessary, which should be at least three times more accurate than the evaluated dataset (Maune, 2007). In this study the evaluation check was conducted by comparing the DEM heights with elevation data from the Geoscience Laser Altimeter System (GLAS) instrument aboard the NASA Ice, Cloud, and land Elevation satellite. Although the primary objectives of the ICESat mission focus on polar ice sheet mass balance, the $14^{\text {th }}$ product ICESat/GLA14 data also provides altimetry data with high vertical accuracy of $0.1 \mathrm{~m}$ for flat locations and $1 \mathrm{~m}$ for undulated terrain (Schutz et al., 2005, Duong et al., 2009). Several studies showed a successful vertical accuracy assessment 
over a broader regional extent with ICESat data (Huang et al., 2011, Zhao et al., 2017).

For accuracy assessment all elevations were transferred to WGS84 ellipsoid as vertical datum. To detect outliers, e.g. from cloud reflections, all ICESat points with a height difference value greater than $60 \mathrm{~m}$ compared to the TanDEM-X heights were eliminated prior the evaluation. Finally, a total amount of around 450,000 points was used to evaluate the accuracy of the regional elevation models. For the local elevation models an average amount of 500 elevation points was used for each scene.

Accuracy values are only comparable if they can be related to the existing relief, since it is evident that different landscapes affect the accurateness of DEMs (Mukherjee et al., 2013). Therefore, to relate the accuracy of digital elevation models to specific terrain characteristics, several terrain parameters were calculated. The topographic roughness index (TRI) was computed and divided into seven classes after Riley et al. (1999) from levelled surfaces to extremely rugged terrain. The slope was calculated and classified into five classes from flat $\left(<5^{\circ}\right)$, gentle $\left(5^{\circ}-15^{\circ}\right)$, moderate $\left(15^{\circ}-25^{\circ}\right)$, steep $\left(25^{\circ}-35^{\circ}\right)$ to extreme $\left(>35^{\circ}\right)$. Additionally, the topographic position index (TPI) after Weiss (2001) was computed to assign the height errors to specific landforms. The number of classes was reduced to seven by combining the three ridge classes and two drainage classes to one class each. This evaluation was only conducted for all global available datasets as the coverage region of the others was too small to gain enough evaluation data for all classes. All landforms and terrain features were derived over the whole region on the basis of the $12 \mathrm{~m}$ TanDEM-X DEM.

To evaluate the accuracy of the DEMs for large scale terrain, the height accuracy was compared to nine elevation models derived with UAV-based photogrammetry with very high resolution. These DEMs were achieved by imagery captured with a 12 megapixel FC330 camera and a $20 \mathrm{~mm}$ full frame equivalent lens, fixed by a shock-absorbent gimbal on a rotary-wing quadrocopter (type: DJI Phantom 4), set to capture images every 10 secs. Camera was set to shutter speed priority (1/1000) with ISO-100. Flights at all sites were manually conducted between 10 am and 12 am local time on cloud-free days in a line-based pattern at two different heights, flying slower than $2.5 \mathrm{~ms}^{-1}$. Missions result in a high overlap of $>9$ images per point. Subsequent image processing was conducted with AgiSoft Photoscan Professional (vers. 1.4.2). Images were aligned using the direct GPS measurements of the UAV recorded for each image. Processing in ultra-high quality for the dense point cloud generation resulted in a mean ground pixel resolution of $1 \mathrm{~cm}$ to $8 \mathrm{~cm}$ for the DEM and each scene covers an average area of $0.04 \mathrm{~km}^{2}$. All data was exported in WGS84 UTM Zone 19S (EPSG: 32719). To evaluate the vertical accuracy of all DEMs their spatial resolution was up-sampled to the resolution of the UAV elevation models. Then pixel-wise errors were derived by subtracting the heights of UAV derived DEMs from the other elevation models.

From all height errors the root mean square error (RMSE) was calculated with the following equation:

$$
R M S E=\sqrt{\frac{\left(\sum_{\mathrm{i}=1}^{\mathrm{n}}\left(\Delta \mathrm{h}_{\mathrm{i}}\right)^{2}\right)}{\mathrm{n}}}
$$

where $\quad \Delta h_{i}=$ elevation difference between assessed DEM and reference DEM.

$n=$ number of pixels.
Furthermore, the normalized median absolute deviation (NMAD) was also conducted, as this accuracy measure is more robust against non-normal error distributions and outliers (Höhle \& Höhle, 2009). The equation is:

$$
N M A D=1.4826 \times \operatorname{median}\left(\left|\Delta h_{i}-m_{\Delta h}\right|\right)
$$

where $\quad \Delta h_{i}=$ elevation difference between assessed DEM and reference DEM.

$m_{\Delta h}=$ median of all elevation differences.

\section{RESULTS}

The determined overall accuracies compared to ICESat altitude points are listed in Table 1. The highest accuracies were measured for the $12 \mathrm{~m}$ TanDEM-X with a RMSE of $2.3 \mathrm{~m}$ and a NMAD of $0.8 \mathrm{~m}$. The lowest were detected for the $30 \mathrm{~m}$ ASTER GDEM with a RMSE of $8.9 \mathrm{~m}$ and a NMAD of $7.1 \mathrm{~m}$. Thus, for this DEM a lower overall accuracy has been detected than for both $90 \mathrm{~m}$ datasets. For the TanDEM-X with a resolution of $90 \mathrm{~m}$ a rather high difference between RMSE and NMAD can be observed. For the DEMs with local coverage the accuracies vary between $1.1 \mathrm{~m}$ (RMSE and NMAD) for the SPOT Pampa de Tana scene and a RMSE of $5.6 \mathrm{~m}$ for the Pléiades Badlands scene. In comparison, NMAD of the Pléiades Badlands DEM is rather low with $1.5 \mathrm{~m}$. The highest NMAD was measured for the SPOT 116 scene.

\begin{tabular}{lllll}
\hline DEM & $\begin{array}{l}\text { Res. } \\
{[\mathbf{m}]}\end{array}$ & $\begin{array}{l}\text { RMSE } \\
{[\mathbf{m}]}\end{array}$ & $\begin{array}{l}\text { NMAD } \\
{[\mathbf{m}]}\end{array}$ & $\begin{array}{l}\text { ICESat } \\
\text { Points }\end{array}$ \\
\hline TanDEM-X & 12 & 2.3 & 0.8 & 453434 \\
SRTM & 30 & 5.4 & 4.6 & 453434 \\
ASTER GDEM & 30 & 8.9 & 7.1 & 453434 \\
TanDEM-X & 90 & 6.4 & 2.1 & 453434 \\
SRTM & 90 & 6.5 & 4.9 & 453434 \\
ALOS W3D & 30 & 3.6 & 2.4 & 447372 \\
Pléiades C & 5 & 4.5 & 3.7 & 629 \\
Pléiades S & 5 & 2.3 & 1.3 & 273 \\
Pléiades Badlands & 5 & 5.6 & 1.5 & 158 \\
Pléiades Rio Loa East & 5 & 1.6 & 0.9 & 634 \\
Pléiades Rio Loa West & 5 & 3.3 & 1.4 & 475 \\
Spot 116 & 5 & 5.1 & 3.9 & 1293 \\
Spot 123 & 5 & 4.2 & 2.7 & 424 \\
Spot 125 & 5 & 5.7 & 3.2 & 958 \\
Spot Pampa de Tana & 5 & 1.1 & 1.1 & 445
\end{tabular}

Table 1. Overall accuracies of all digital elevation models compared to ICESat point data. Listed are the spatial resolution (Res), the calculated root mean square error (RMSE), the normalized median absolute deviation (NMAD) and the total amount of applied ICESat point for each DEM.

The accuracy assessment compared to very high resolution elevation data derived by UAV-based photogrammetry on large scales shows similar results (Tab. 2). Highest values are measured for the $90 \mathrm{~m}$ SRTM DEM (RMSE: 7.5 m, NMAD: $7.8 \mathrm{~m}$ ), the lowest values for the Pléiades S scene (RMSE: $1.6 \mathrm{~m}$, NMAD: $1.3 \mathrm{~m}$ ) and the $12 \mathrm{~m}$ TanDEM-X dataset (RMSE: $2.0 \mathrm{~m}$, NMAD: $1.7 \mathrm{~m}$ ). It can be observed here, that the discrepancy between RMSE and NMAD values is lower compared to the evaluation with ICESat points. Furthermore, error values for both 90 m models are greater than with ICESat points. In contrast, the results show for the ASTER GDEM a higher accuracy with a RMSE and NMAD of $5.5 \mathrm{~m}$. Additionally, both Pléiades scenes and the SPOT scene have an increased accuracy as well. 
Especially for Pléiades Badlands the RMSE $(2.4 \mathrm{~m})$ is significantly lower compared to the RMSE from ICESat evaluation $(5.6 \mathrm{~m})$.

\begin{tabular}{lllll}
\hline DEM & $\begin{array}{l}\text { Res. } \\
{[\mathbf{m}]}\end{array}$ & $\begin{array}{l}\text { RMSE } \\
{[\mathbf{m}]}\end{array}$ & $\begin{array}{l}\text { NMAD } \\
{[\mathbf{m}]}\end{array}$ & $\begin{array}{l}\text { No. of UAV } \\
\text { DEMs }\end{array}$ \\
\hline TanDEM-X & 12 & 2.0 & 1.7 & 9 \\
SRTM & 30 & 4.7 & 4.8 & 9 \\
ASTER GDEM & 30 & 5.5 & 5.5 & 9 \\
TanDEM-X & 90 & 7.1 & 7.1 & 9 \\
SRTM & 90 & 7.5 & 7.8 & 9 \\
ALOS W3D & 30 & 3.3 & 3.1 & 9 \\
Pléiades S & 5 & 1.6 & 1.3 & 2 \\
Pléiades Badlands & 5 & 2.4 & 2.3 & 2 \\
Spot 123 & 5 & 3.7 & 3.3 & 2 \\
\hline
\end{tabular}

Table 2. Overall accuracies of the digital elevation models compared to very high resolution DEMs derived by UAV. Listed are the spatial resolution (Res), the calculated root mean square error (RMSE), the normalized median absolute deviation (NMAD) and the total amount of UAV DEMs.

The results depicted in Figure 2 show the RMSE and NMAD of all digital elevation models according to their Topographic roughness index. Both values were only calculated, when at least ten points were available for the corresponding dataset. Classes with less than ten points were not considered in this study. Furthermore, the SPOT 125 scene was not considered here as a sufficient amount of points was available only for class 'extremely rugged'.
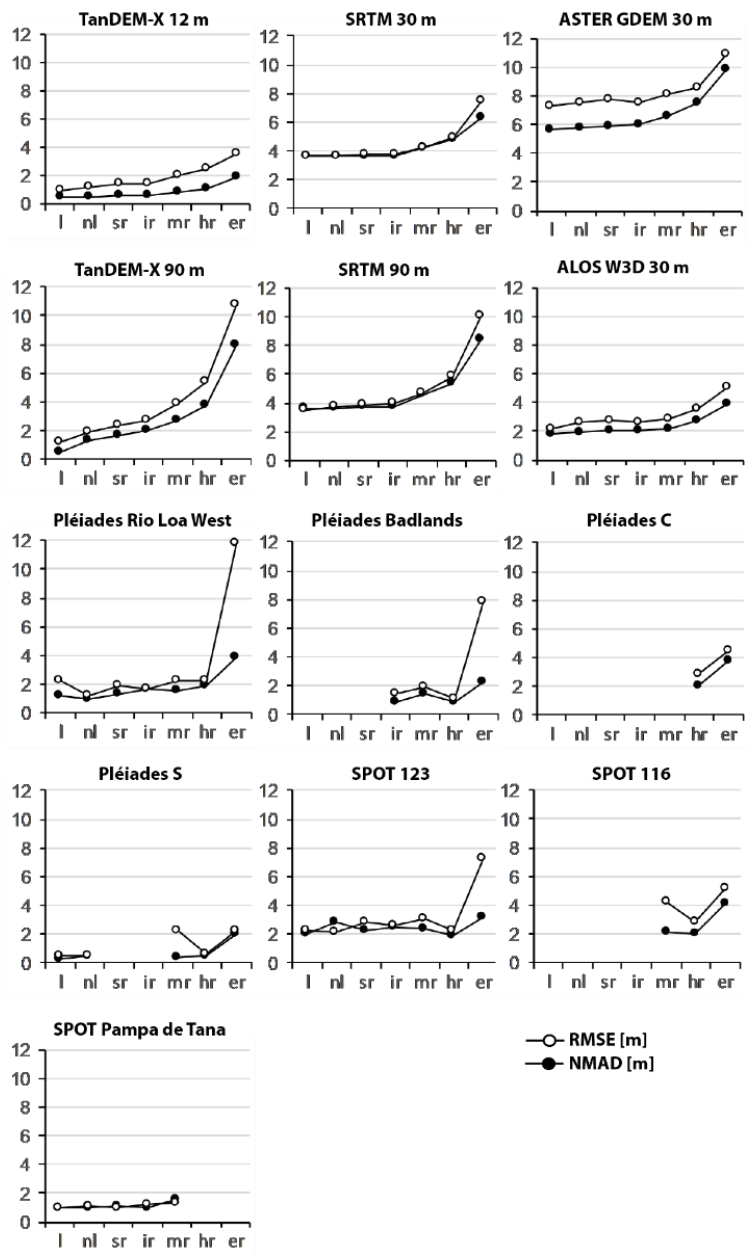

Figure 2. Calculated RMSE of elevation differences according to the classified Topographic Roughness Index from level to extremely rugged. Categorization of classes was conducted after Riley et al. (1999). Classes are level (1), nearly level (nl), slightly rugged (sr), intermediate rugged (ir), moderately rugged (mr), highly rugged (hr), extremely rugged (er).

The diagram shows for most elevation models only a slight increase of error from class 'level' to class 'highly rugged'. For both DEMs with a $90 \mathrm{~m}$ spatial resolution a higher increase of uncertainty is detectable from 'intermediate rugged' terrain to 'extremely rugged' terrain. For all elevation models the biggest loss in accuracy is visible in the category 'extremely rugged'. Especially for the $90 \mathrm{~m}$ TanDEM-X a very high accuracy is detectable in level terrain, which is similar to the $12 \mathrm{~m}$ TanDEM$\mathrm{X}$. But in rough terrain the accuracy decreases more than for all other DEMs and is lower than for the SRTM $90 \mathrm{~m}$ DEM in 'extremely rugged' terrain. The freely available ALOS W3D dataset shows a better overall accuracy and terrain independency, than previously noted DEMs.

The highest accuracies according to their topographic roughness were detected for the high resolution Pléiades S DEM both in flat and rough terrain. Lowest accuracies were detected for the $30 \mathrm{~m}$ ASTER GDEM. Only in category 'extremely rugged' the $90 \mathrm{~m}$ TanDEM-X and $90 \mathrm{~m}$ SRTM perform with similar error values. For the Pléiades Rio Loa West and Pléiades Badlands DEMs a strong increase of RMSE is detectable in the category 'extremely rugged', whereas the RMSE is rather low for these DEMs in all other categories. Furthermore, the NMAD of these two elevation models in the highest category is also rather low and does not show such an increase of error.
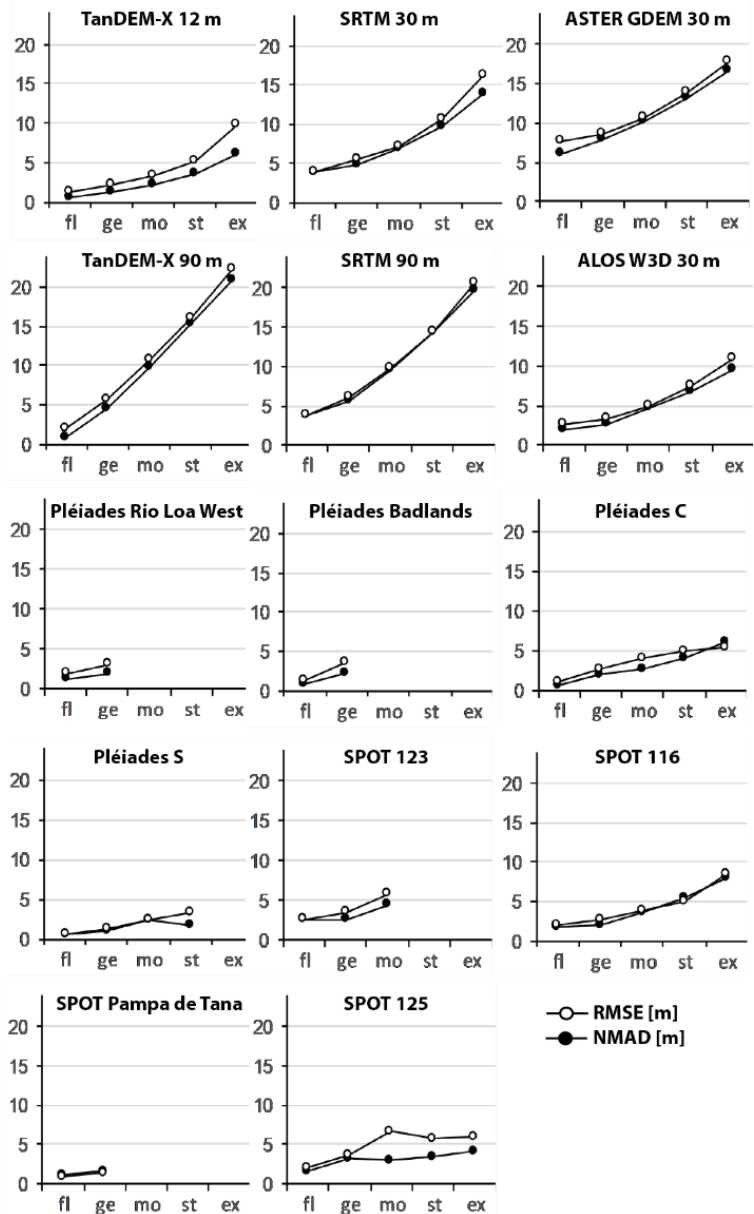

Figure 3. Calculated RMSE and NMAD of elevation differences according to the slope. Derived slope classes are flat (fl), gentle (ge), moderate (mo), steep (st) and extreme (ex). 
Figure 3 shows the RMSE and NMAD of all elevation models according to their slope. For all DEMs is an increase of RMSE and NMAD noticeable for steeper slopes. Especially for DEMs with lower spatial resolution a stronger decrease of accuracy is detectable for rising slope degrees. Thus, the $90 \mathrm{~m}$ SRTM (RMSE: $20.6 \mathrm{~m}$, NMAD $19.6 \mathrm{~m}$ ) and the $90 \mathrm{~m}$ TanDEM-X (RMSE: $22.2 \mathrm{~m}$, NMAD $21.0 \mathrm{~m}$ ) have the lowest accuracies here.

Generally, the local DEMs derived from Pléiades and SPOT scenes achieve the lowest RMSE and NMAD values. Though, the diagram curves indicate a slightly higher accuracy for Pléiades datasets compared to SPOT datasets. For very steep slopes only the TanDEM-X with a spatial resolution of $12 \mathrm{~m}$ is able to achieve similar accuracy values (RMSE: $9.7 \mathrm{~m}$, NMAD: $6.0 \mathrm{~m}$ ) compared to the high resolution local DEMs, which have an average accuracy of RMSE $6.6 \mathrm{~m}$ and NMAD of $6.1 \mathrm{~m}$ here.

Figures 4 and 5 show for all global available DEMs their RMSE and NMAD according to their respective TPI landform class. The results show for all elevation models the lowest RMSE and NMAD values for the class 'plains'. The highest error values were determined for the landform classes 'gully', 'drainage' and 'ridge'. The highest accuracies are calculated for the $12 \mathrm{~m}$ TanDEM-X, which has also the lowest error values for class 'plains' (RMSE: $1.0 \mathrm{~m}$, NMAD: $1.1 \mathrm{~m}$ ) and the highest RMSE for class 'drainage' with $5.0 \mathrm{~m}$. For the NMAD calculation the highest error values are determined for the classes 'gully' and 'drainage' with $2.4 \mathrm{~m}$.

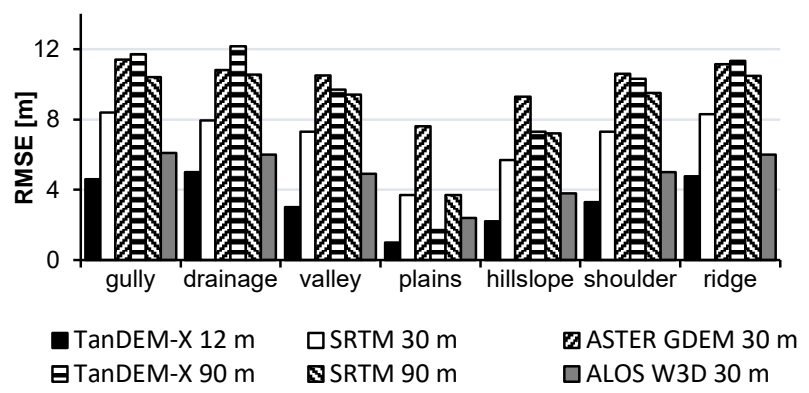

Figure 4. Calculated RMSE of elevation according to TPI classes classified with $12 \mathrm{~m}$ TanDEM-X.

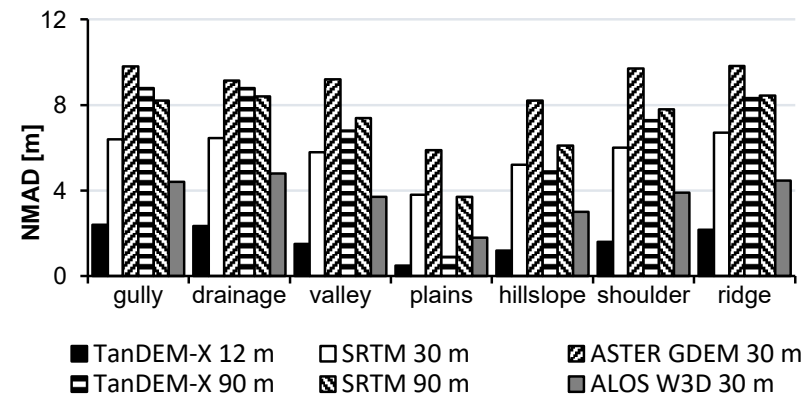

Figure 5. Calculated NMAD of elevation differences according to TPI classes classified with $12 \mathrm{~m}$ TanDEM-X.

For the most landform classes, the lowest accuracies are measured for the $30 \mathrm{~m}$ ASTER GDEM with values between $7.6 \mathrm{~m}$ (RMSE) and $5.9 \mathrm{~m}$ (NMAD) for class 'plains' and $11.4 \mathrm{~m}$ (RMSE) and $9.8 \mathrm{~m}$ (NMAD) for class 'gully'. Only the calculated RMSE for the $90 \mathrm{~m}$ TanDEM-X DEM was even higher for the classes 'gully', 'drainage' and 'ridge' with values of $11.7 \mathrm{~m}$, $12.2 \mathrm{~m}$ and $11.3 \mathrm{~m}$. The highest NMAD values are calculated for the ASTER GDEM in all classes. The biggest differences in accuracy are also observable here for the $90 \mathrm{~m}$ TanDEM-X elevation model. Whereas its error values are very low for class 'plains' (RMSE: $1.7 \mathrm{~m}$, NMAD: $0.9 \mathrm{~m}$ ) they rise significantly for all other classes. Again the ALOS W3D shows a better overall performance than the $90 \mathrm{~m}$ TanDEM-X DEM.

\section{DISCUSSION}

The results show, as expected, for all DEMs a decreasing accuracy in rougher terrain compared to flat landscapes. This trend is evident for all derived terrain landforms and features. Especially the results of local DEMs derived from stereo satellite imagery show a varying overall accuracy, which highly depends on the topography covered by the scene. Relating them to slope or TRI tends in most cases to lower error values compared to the globally available elevation models.

It can be observed that for most elevation models the RMSE values are higher for the regional evaluation with ICESat points compared to the large scale analysis with DEM data from UAV. Only for both $90 \mathrm{~m}$ DEMs all measured accuracies are lower in the local scale evaluation. The results reveal that this very smallsized relief is much better represented by elevation models with higher spatial resolution. This is in contradiction to the NMAD values. Except for the ASTER GDEM, they are higher for all DEMs in the local scale evaluation. Furthermore, in comparison to the overall accuracies with ICESat elevation points it is noticeable that the differences between RMSE and NMAD values are lower for the UAV accuracy assessment. This possibly indicates that the ICESat dataset has more outliers and the NMAD values are the more robust values here to compare the accuracy for both scales.

For the globally available elevation datasets only the $12 \mathrm{~m}$ TanDEM-X was able to achieve similar accuracies in comparison to the local available DEMs derived from Pléiades and SPOT imagery. These results are in confirmation with other studies, which also showed very high accuracies for the $12 \mathrm{~m}$ TanDEM$\mathrm{X}$ and lower accuracies for the other datasets (Grohmann, 2018, Wessel et al., 2018). It is possible that the high accuracy values of TanDEM-X are affected by the fact that $10 \%$ of the ICESat points were used for block adjustments during the generation process (Huber et al., 2009; Gruber et al., 2012). Also for the processing of the ALOS W3D DEM ICESat elevation points were used (Takaku et al., 2016). Thus, some correlation between those DEMs and the evaluation dataset cannot be excluded. However, the results of the evaluation with completely independent elevation data from UAV measurements produced similar results. Hence, all results of this study appear consistent and a significant correlation cannot be observed here.

The evaluation with ICESat elevation points in consideration of specific landscape features show for elevation models with coarser spatial resolution a higher decrease in accuracy compared to high resolution elevation models. Especially for the $90 \mathrm{~m}$ TanDEM-X a very high drop in accuracy can be observed here. While it achieves similar accuracies as very high resolution elevation models derived from stereo satellite imagery in flat landscapes, it has the lowest overall accuracies in rough terrain with steep slopes. A similar trend with a strong decrease in accuracy was produced by the $90 \mathrm{~m}$ SRTM elevation model. Therefore, it can be concluded that these DEMs are not suitable for large scale terrain analyses, especially in rough landscapes. Also for the ASTER GDEM the results show that the accuracy of this DEM is already lower in flat landscapes than the accuracy of high resolution DEMs in rough terrain. Thus, for this DEMs the results indicate a least suitability for geomorphometric analyses here. The freely available ALOS W3D shows a good agreement 
with both evaluation scales and is more stable over all terrain types, slopes and landforms, only slightly worse than the TanDEM-X 12 m dataset.

\section{CONCLUSION}

In this contribution the influence of relief on the accuracy of digital elevation models was investigated. The results reveal that the rougher and steeper the landscape is the higher resolutions are necessary to depict the landscape in an accurate way. This applies for a regional coverage, but even more for analyses on a local scale. The evaluation was conducted by relating the accuracy values to several extracted terrain features and landforms on a regional scale. Further studies could investigate how the accuracy conducts on large scale terrain features.

The results point out that of all globally available datasets only the TanDEM-X $12 \mathrm{~m}$ and partly the $30 \mathrm{~m}$ ALOS World 3D are able to depict the landscape in the same accuracy as the elevation models with a spatial resolution of $5 \mathrm{~m}$. Thus, it can be assumed that the $12 \mathrm{~m}$ TanDEM-X data is suitable not only for global scale analyses, but as well for local scale studies. All other freely worldwide available elevation models were not able to achieve promising accuracies here and seem less suitable for delineating small terrain features in large scales.

\section{ACKNOWLEDGEMENTS}

Field data provision and financing is funded by the Deutsche Forschungsgemeinschaft (DFG, German Research Foundation) Projektnummer 268236062 - SFB 1211. The TanDEM-X WorldDEM $^{\mathrm{TM}}$ data is provided by a DLR Science grant, 2017.

\section{REFERENCES}

Bishop, M.P., James, L.A., Shroder, J.F., Walsh, S.J., 2012. Geospatial technologies and digital geomorphological mapping: Concepts, issues and research. Geomorphology, 137, 5-26. doi.org/10.1016/j.geomorph.2011.06.027.

Drysa, J., Kumar, D., 2016. Comparison of digitally delineated stream networks from different spaceborne digital elevation models: A case study based on two watersheds in South India. Arab. J. Geosci., 9(18). doi.org/10.1007/s12517-016-2726-x.

Duong, H., Lindenbergh, R., Pfeifer, N., Vosselman, G., 2009. ICESat Full-Waveform Altimetry Compared to Airborne Laser Scanning Altimetry Over The Netherlands. Ieee Transactions on Geoscience and Remote Sensing, 47(10), 3365-3378.

Farr, T.G., Rosen, P.A., Caro, E., Crippen, R., Duren, R., Hensley, S., Kobrick, M., Paller, M., Rodriguez, E., Roth, L Seal, D., Shaffer, S., Shimada, J., Umland, J., Werner, M., Oskin, M., Burbank, D., Alsdorf, D., 2007. The shuttle radar topography mission. Reviews of Geophysics, 45(2), 1-43.

Grieve, S.W.D., Mudd, S.M., Hurst, M.D., 2016a. How long is a hillslope? Earth Surf. Process. Landforms 41, 1039-1054. doi.org/10.1002/esp.3884.

Grieve, S.W.D., Mudd, S.M., Milodowski, D.T., Clubb, F.J., Furbish, D.J., 2016b. How does grid-resolution modulate the topographic expression of geomorphic processes? Earth Surf. Dynam., 4, 627-653. doi.org/10.5194/esurf-4-627-2016.
Grohmann, C.H., 2018. Evaluation of TanDEM-X DEMs on selected Brazilian sites: Comparison with SRTM, ASTER GDEM and ALOS AW3D30. Remote Sensing of Environment, 212, 121-133. doi.org/10.1016/j.rse.2018.04.043.

Gruber, A., Wessel, B., Huber, M., Roth, A., 2012. Operational TanDEM-X DEM calibration and first validation results. ISPRS Journal of Photogrammetry and Remote Sensing, 73, 39-49. doi.org/10.1016/j.isprsjprs.2012.06.002.

Höhle, J., Höhle, M., 2009. Accuracy assessment of digital elevation models by means of robust statistical methods. ISPRS Journal of Photogrammetry and Remote Sensing, 64(4), 398406. doi.org/10.1016/j.isprsjprs.2009.02.003.

Holmes, K.W., Chadwick, O.A., Kyriakidis, P.C., 2000. Error in a USGS 30-meter digital elevation model and its impact on terrain modelling. Journal of Hydrology, 233(1-4), 154-173. doi.org/10.1016/S0022-1694(00)00229-8.

Huang, X., Xie, H., Liang, T., Yi, D., 2011. Estimating vertical error of SRTM and map-based DEMs using ICESat altimetry data in the eastern Tibetan Plateau. International Journal of Remote Sensing, 32(18), 5177-5196. doi.org/10.1080/01431161. 2010.495092

Huber, M., Wessel, B., Kosmann, D., Felbier, A., Schwieger, V., Habermeyer, M., Wendleder, A., Roth, A., 2009. Ensuring globally the TanDEM-X height accuracy: Analysis of the reference data sets ICESat, SRTM and KGPS-tracks. IEEE International Geoscience and Remote Sensing Symposium 2009, Cape Town, South Africa.

Kramm, T., Hoffmeister, D., Curdt, C., Maleki, S., Khormali, F., Kehl, M., 2017. Accuracy Assessment of Landform Classification Approaches on Different Spatial Scales for the Iranian Loess Plateau. ISPRS International Journal of GeoInformation, 6(11), 366. doi.org/10.3390/ijgi6110366.

Leempoel, K., Parisod, C., Geiser, C., Dapra, L., Vittoz, P., Joost, S., 2015. Very high-resolution digital elevation models: are multi-scale derived variables ecologically relevant? Methods in Ecology and Evolution, 6(12), 1373-1383. doi.org/10.1111/ 2041-210X.12427.

Maune, D.F., 2007. Digital Elevation Model Technologies and Applications: The DEM User Manual, 2nd ed.

Mukherjee, S., Joshi, P.K., Mukherjee, S., Ghosh, A., Garg, G.D., Mukhopadhyay, A., 2013. Evaluation of vertical accuracy of open source Digital Elevation Model (DEM). International Journal of Applied Earth Observation and Geoinformation, 21 , 205-217. doi.org/10.1016/j.jag.2012.09.004.

Riley, S. J., DeGloria, S.D., Elliot, R., 1999. A terrain ruggedness index that quantifies topographic heterogeneity. Intermountain Journal of Sciences, 5(1-4), 23-27.

Schutz, B.E., Zwally, H.J., Shuman, C.A., Hancock, D., DiMarzio, J.P., 2005. Overview of the ICESat Mission. Geophysical Research Letters, 32(21).

Tadono, T., Ishida, H., Oda, F., Naito, S., Minakawa, K., Iwamoto, H., 2014. Precise Global DEM Generation by ALOS PRISM. ISPRS Ann. Photogramm. Remote Sens. Spatial Inf. Sci., II-4. doi.org/71-76. 10.5194/isprsannals-II-4-71-2014. 
Takaku, J., Tadono, T., Tsutsui, K., 2014. Generation of High Resolution Global DSM from ALOS PRISM. Int. Arch. Photogramm. Remote Sens. Spatial Inf. Sci., XL-4, 243-248. doi.org/10.5194/isprsarchives-XL-4-243-2014.

Takaku, J., Tadono, T., Tsutsui, K., Ichikawa, M., 2016. Validation of 'AW3D' Global DSM generated from ALOS PRISM. Int. Ann. Photogramm. Remote Sens. Spatial Inf. Sci., III-4, 25-31. doi.org/10.5194/isprsannals-III-4-25-2016.

Weiss, A.D., 2001. Topographic Position and Landforms Analysis. ESRI Users Conference, July 9-13, 2001, San Diego, USA.

Wessel, B., Huber, M., Wohlfart, C., Marschalk, U., Kosmann, D., Roth, A., 2018. Accuracy assessment of the global TanDEM$\mathrm{X}$ Digital Elevation Model with GPS data. ISPRS Journal of Photogrammetry and Remote Sensing 139, 171-182. doi.org/10.1016/j.isprsjprs.2018.02.017.

Zhao, S., Cheng, W., Zhuo, C., Liu, H., Su, Q., Zhang, S., He, W., Wang, L., Wu, W., 2017. Using MLR to model the vertical error distribution of ASTER GDEM V2 data based on ICESat/GLA14 data in the Loess Plateau of China. Zeitschrift für Geomorphologie, 61(2), 9-26. doi.org/10.1127/zfg_supp1/2016/ 0325 . 